\title{
ACTIVIDADES 2011
}

Nacionales:

Congreso de Logoterapia y Análisis Existencial 18-20 de noviembre de 2010

Montevideo, Uruguay

$9^{\circ}$ Congreso Nacional de la Sociedad de Psiquiatría del Uruguay

5-7 de mayo de 2011

Montevideo, Uruguay

$20^{\circ}$ Jornadas Uruguayas de Psicología

24-25 de junio 2011

Montevideo, Uruguay

INTERNACIONALES:

$2^{\circ}$ Congreso Internacional de Investigación y Práctica Profesional en Psicología, $17^{\circ}$ Jornada de Investigación y $6^{\circ}$ Encuentro de Investigadores en Psicología del MERCOSUR.

22-24 de noviembre de 2010

Buenos Aires, Argentina

$6^{\circ}$ Conferencia Africana de Psicoterapia

14-16 de diciembre de 2010

Kampala, Uganda

$12^{\circ}$ Congreso Virtual de Psiquiatría. Interpsiquis 1-28 de febrero de 2011

$4^{\circ}$ Congreso Internacional de Psicología Legal 1-6 de marzo de 201

Miami, FL, U.S.A

$4^{\circ}$ Congreso Internacional de Salud Mental de la Mujer

16-19 de marzo de 2011

Madrid, España

Reunión Bienal de la Sociedad para la Investigación del Desarrollo Infantil

31 de marzo al 2 de abril de 2011

Montreal, Quebec, Canadá

$13^{\circ}$ Congreso Internacional sobre la Investigación en Esquizofrenia

2-6 de abril de 2011

Colorado Springs, Colorado, USA

$6^{\circ}$ Congreso Latinoamericano de Psicología de la Salud

18-20 de mayo de 2011

Xalapa, Veracruz, México

$15^{\circ}$ Congreso Europeo de Psicología Organizacional

25-28 de mayo de 2011

Maastricht, Holanda $5^{\circ}$ Conferencia Anual Internacional de Psicología 30 de mayo al 2 de junio de 2011

Athenas, Grecia

$7^{\circ}$ Congreso Internacional de Psicoterapia Cognitiva

2-5 de junio de 2011

Estambul, Turquía

$33^{\circ}$ Congreso Interamericano de Psicología

26-30 de junio de 2011

Medellin, Colombia

$12^{\circ}$ Congreso Europeo de Psicología

4-8 de julio de 2011

Estambul, Turquía

$2^{\circ}$ Conferencia Internacional de Counseling

7-8 de julio de 2011

Hong Kong, China

Reunión Anual de la Sociedad Internacional de Psicología Política

9-12 de julio de 2011

Estambul, Turquía

Conferencia de la Asociación Internacional de Investigación en Psicología Económica

12-16 de julio de 2011

Exeter, Reino Unido

$32^{\circ}$ Conferencia de la Sociedad de Investigación en Estrés y Ansiedad

18-20 de julio de 2011

Münster, Alemania

$2^{\circ}$ Congreso Mundial en Psicología Positiva

23-26 de julio de 2011

Filadelfia, PA, U.S.A

$7^{\circ}$ Conferencia Bienal de la Academia Internacional de Investigación Intercultural

23-26 de julio de 2011

Singapur, Singapur

$15^{\circ}$ Conferencia Europea de Psicología del

Desarrollo

23-27 de agosto de 2011

Bergen, Noruega

Congreso Mundial de Psicoterapia

24-28 de agosto de 2011

Sydney, Australia

$11^{\circ}$ Jornadas Internacionales de Psicología

Educacional

15-17 de setiembre de 2011

Montevideo, Uruguay 